University of Puget Sound

Sound Ideas

Summer Research

Summer 2021

\title{
Comparing 40-year sediment records of aquatic ecosystem evolution in two large lakes in the blast zone of Mount St. Helens
}

\author{
Maeve Gallagher \\ University of Puget Sound \\ Kena Fox-Dobbs \\ University of Puget Sound
}

Avery Shinneman

Angelica Lucchetto

Follow this and additional works at: https://soundideas.pugetsound.edu/summer_research

\section{Recommended Citation}

Gallagher, Maeve; Fox-Dobbs, Kena; Shinneman, Avery; and Lucchetto, Angelica, "Comparing 40-year sediment records of aquatic ecosystem evolution in two large lakes in the blast zone of Mount St. Helens" (2021). Summer Research. 395.

https://soundideas.pugetsound.edu/summer_research/395

This Article is brought to you for free and open access by Sound Ideas. It has been accepted for inclusion in Summer Research by an authorized administrator of Sound Ideas. For more information, please contact soundideas@pugetsound.edu. 


\section{Comparing 40-year sediment records of aquatic ecosystem evolution in two}

\section{large lakes in the blast zone of Mount St. Helens}

Maeve Gallagher ${ }^{1}$, Kena Fox-Dobbs ${ }^{1}$, Avery Shinneman ${ }^{2}$, Angelica Lucchetto ${ }^{2}$, and Jim Gawel ${ }^{3}$

${ }^{1}$ Geology Department, University of Puget Sound, Tacoma, WA; ${ }^{2}$ School of Interdisciplinary Arts and Sciences, University of Washington, Bothell;

${ }^{3}$ School of Interdisciplinary Arts and Sciences, University of Washington, Tacoma.

\section{Introduction}

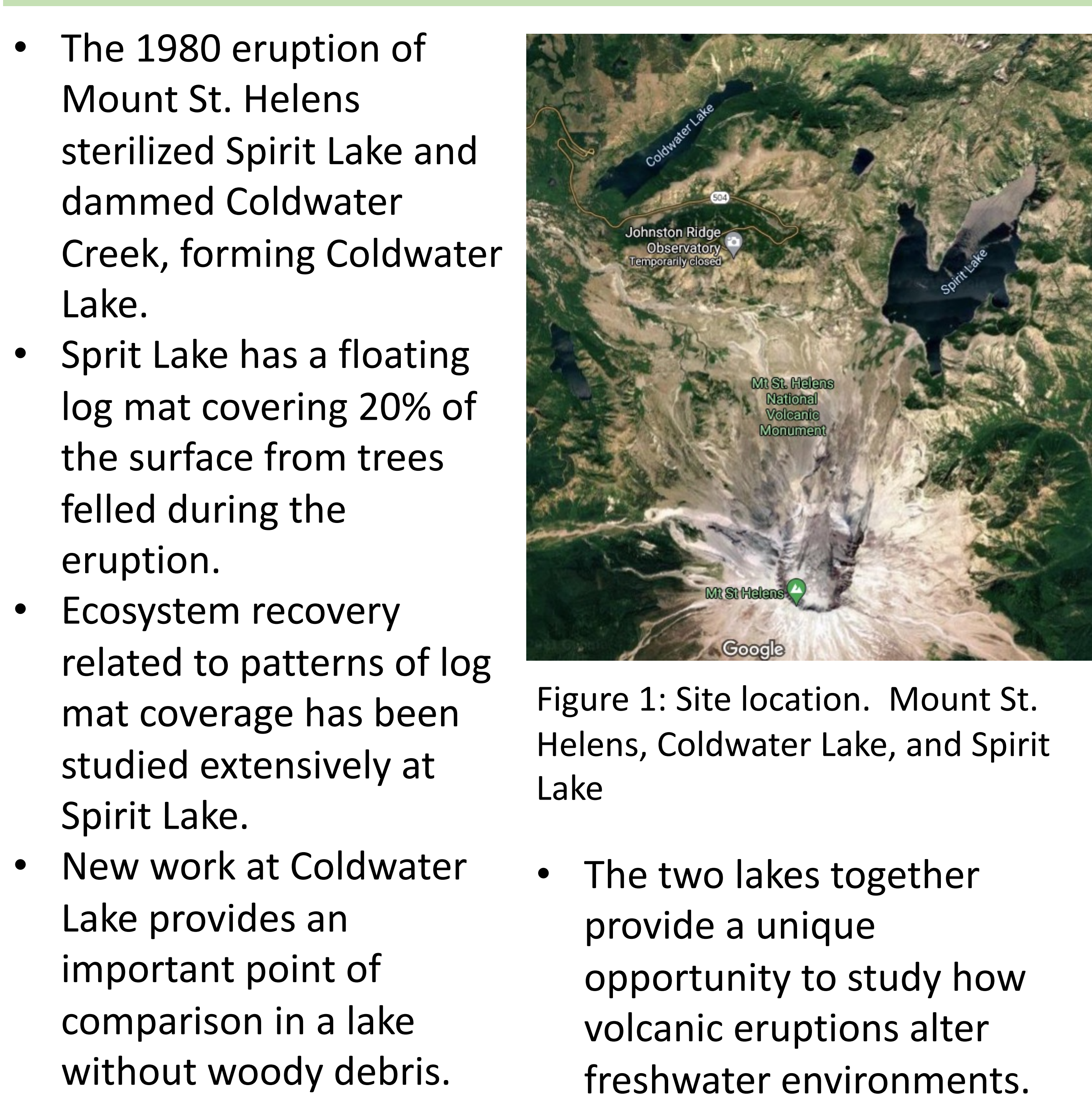

Part One: Temporal Changes in Coldwater Lake Diatom Assemblages

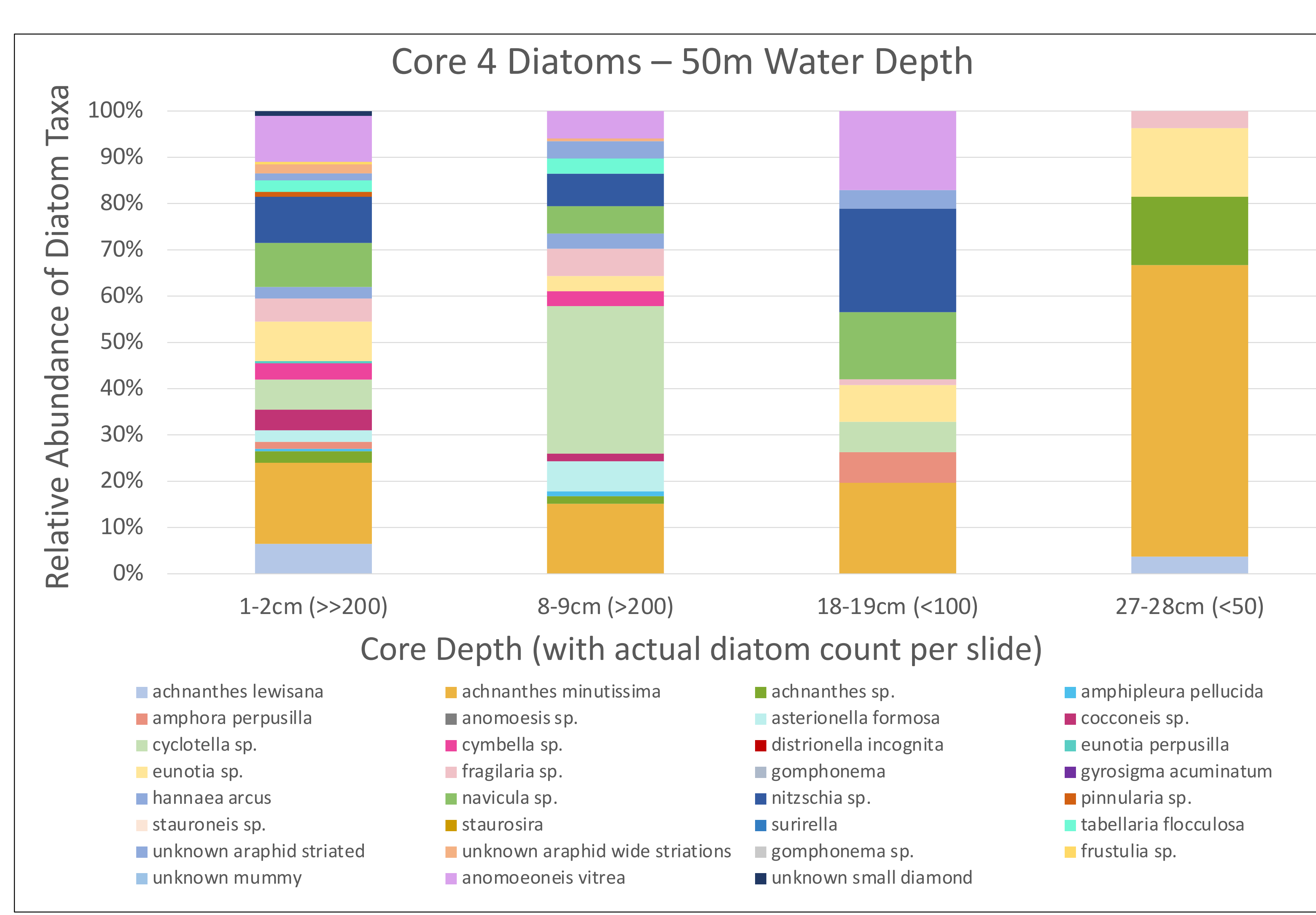

Figure 4: Changes in diatom taxa from the top to the bottom of the deepest core taken at Coldwater Lake.

- Younger sediment displays much more diversity in diatom taxa, as well as a higher abundance of diatoms overall, implying that nutrients and substrate in the lake have increased overtime as the lake has developed.

- There is less change in diversity between the top few centimeters of sediment than between the bottom few centimeters, implying that the lake has become relatively stable in recent years.

\section{Future Work}

- Subsamples will be analyzed for $\% \mathrm{C}$ and $\% \mathrm{~N}$ at the $\mathrm{CU}$ boulder isotope lab in order to track the change in organic matter through time and support preliminary conclusions made from diatom analysis.

- Diatom results will continue to be analyzed in order to better understand how changes in dominant taxa indicate changes in the lake ecosystem.
Field Work

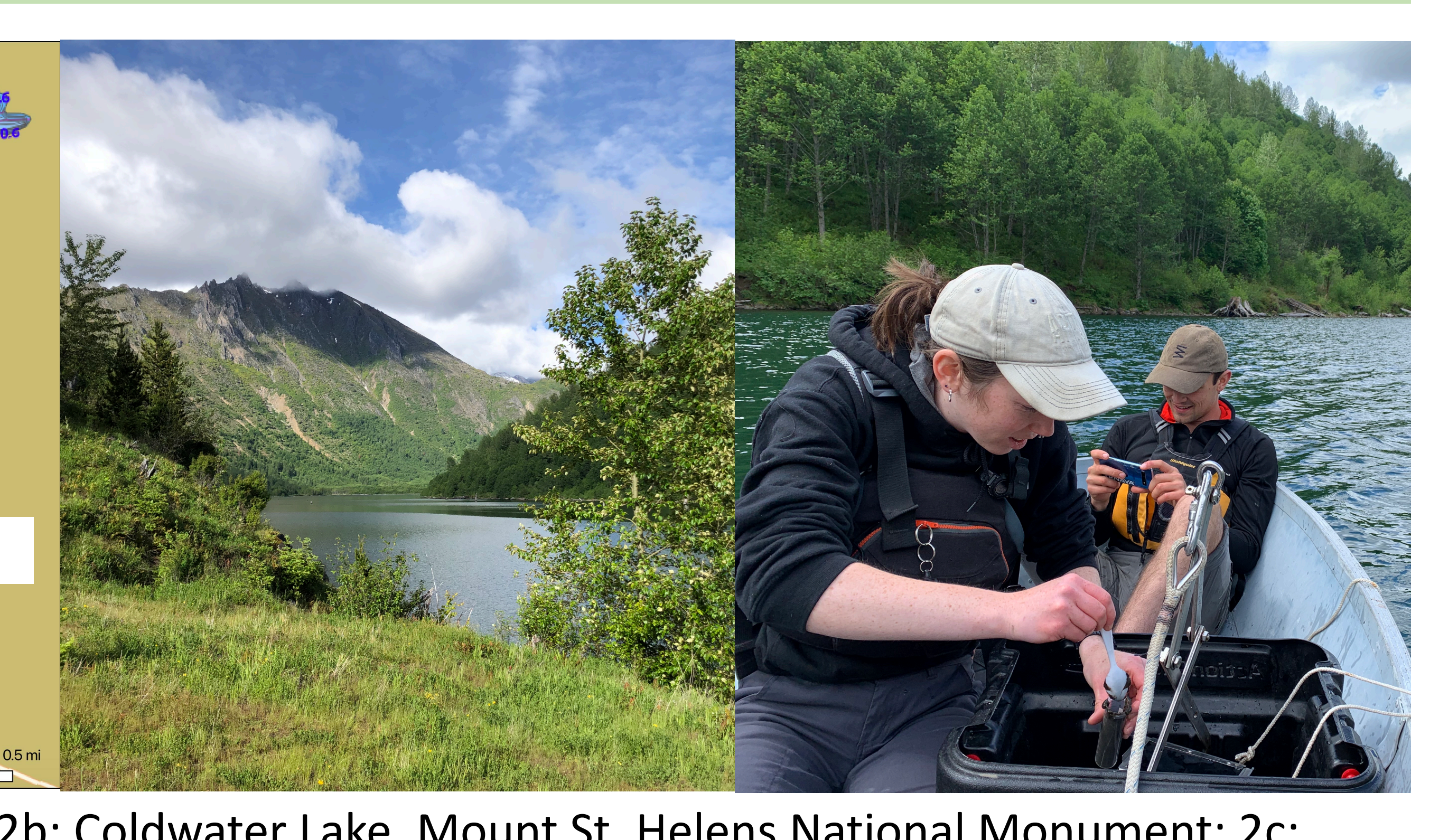

Took four sediment cores using a gravity corer at various flat benches around the lake.

Cores were taken at $9 \mathrm{~m}, 30 \mathrm{~m}, 48 \mathrm{~m}$, and $50 \mathrm{~m}$ water depth; each core was around $30 \mathrm{~cm}$ long.

Took three surface sediment dredge samples between 3-8m depth.

- Took two plankton tow samples at the lake surface

Part Two: Spatial Variability in Coldwater
Lake Diatom Assemblages

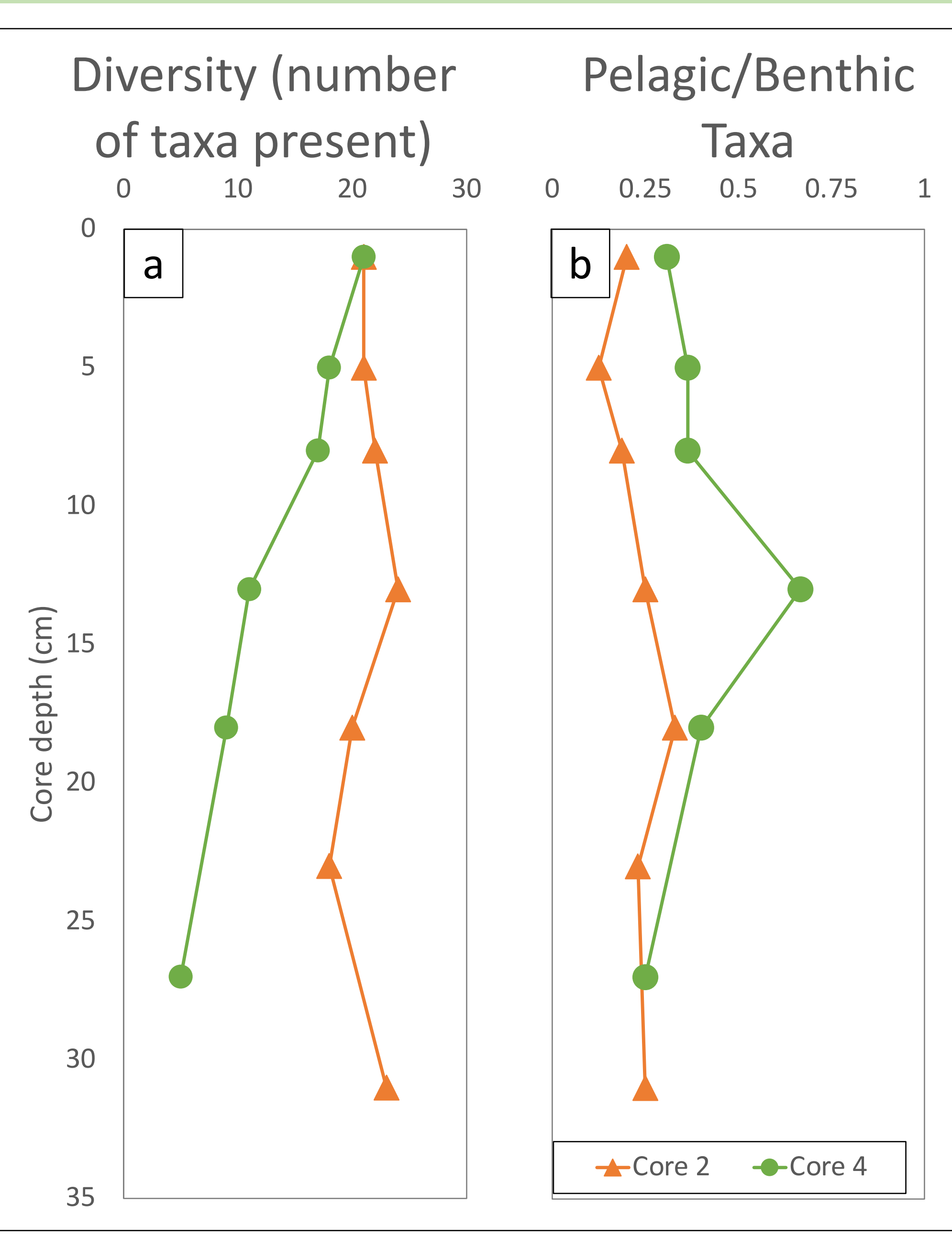

Figure 5a: Diatom diversity with depth in deepest and shallowest cores taken at Coldwater Lake. and shallowest cores taken at Coldwater Lake. Figure 5b: Ratio

- The diversity of taxa in Core 4 has increased overtime, while taxa diversity in Core 2 has remained similar to the top $10 \mathrm{~cm}$ of Core 4

- While Core 4 has had a slightly higher ratio of pelagic to benthic diatom taxa overtime, both cores are consistently dominated by benthic taxa. No pelagic diatoms were seen when studying wet plankton tow samples.

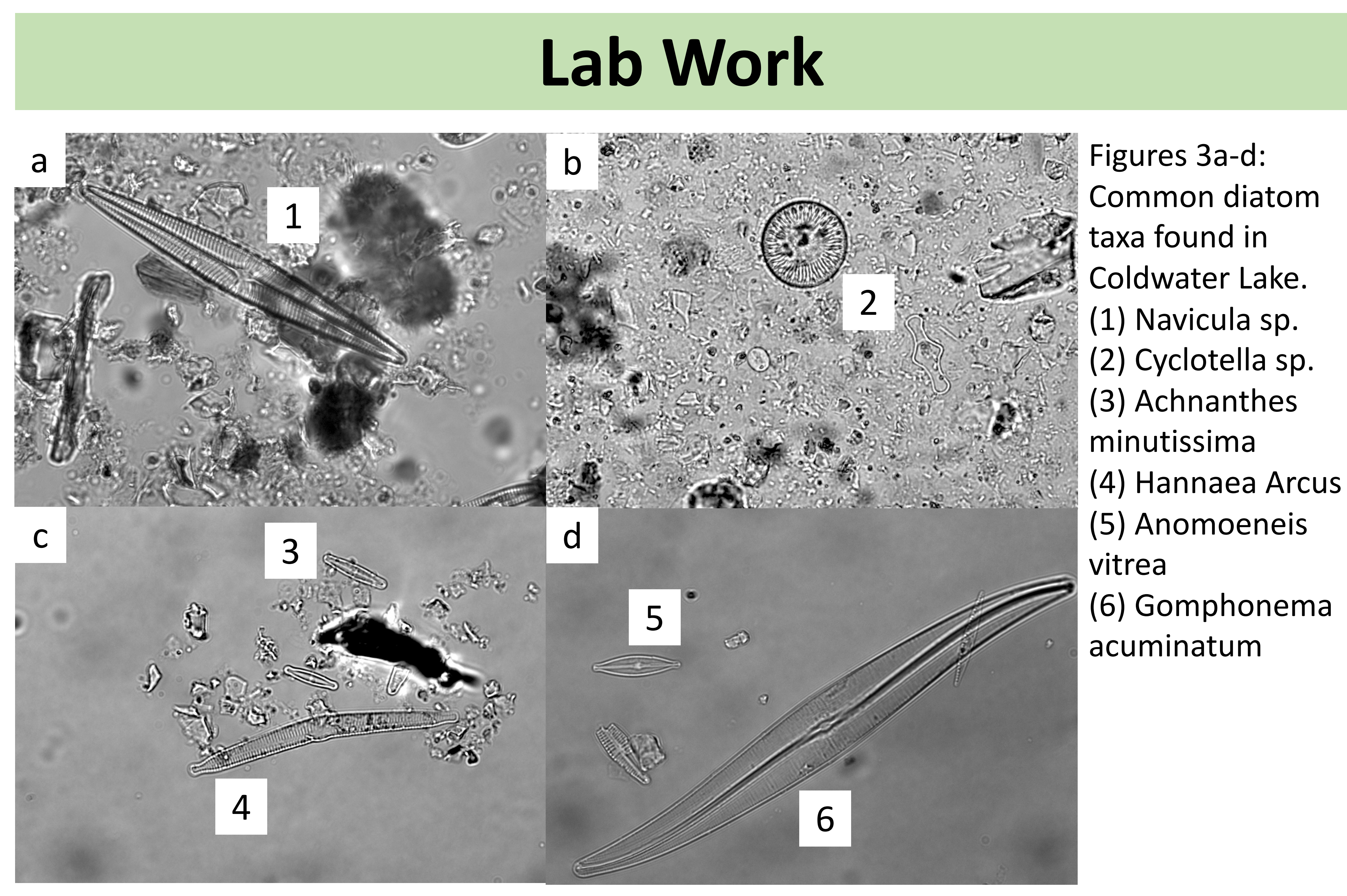

- Extruded and sectioned the cores into $1 \mathrm{~cm}$ intervals

- Dried and weighed subsamples for organic geochemical analysis - Cleaned, prepped, and diluted subsamples to make diatom slides - Identified and counted diatoms from 16 samples

\section{Part Three: Comparing Coldwater Lake and Spirit Lake Diatom Assemblages}

Spirit Lake has a much higher level of pelagic diatoms than Coldwater Lake, implying that Coldwater likely has lower concentrations of nutrients needed to sustain planktonic taxa.

The $P / B$ ratios at Coldwater and Spirit Lakesarenotn Spirit Lakes are not more similar in more like environments (i.e., shallow with no log mat), implying that the presence of the log mat is not the only factor causing differences in the ecosystem recovery history of the two lakes. Spirit Lake had a eutrophic period in its recovery marked by a notable spike in abundance of planktonic diams. Coldwater lake is lacking this spike, Coldwing lat is lacking this spike, implying that it either never went eutrophic, or that our cores didn't reach far enough back

\begin{tabular}{|l|r|}
\hline Sample Location & P/B Average \\
\hline SL shallow, no log mat & 0.580 \\
CWL shallow, no log mat & 0.225 \\
SL deep, with log mat & 0.448 \\
CWL deep, no log mat & 0.392 \\
SL Average & 0.507 \\
CWL Average & 0.302 \\
\hline \multicolumn{2}{|l|}{ Table 1: Ratios of pelagic to benthic taxa in }
\end{tabular}
Table 1: Ratios of pelagic to benthic taxa in various locations in Spirit and Coldwater Lakes.

Much of the differences between the two lakes can be explained by the differences in their geologic formations. Spirit Lake was directly in the path of the debris flow, causing an influx of nutrients, while Coldwater Lake was formed as a brand-new lake on top of a stream bed.

Despite these differences, both lakes appear to have stabilized and reached ecological equilibrium after their recovery from the eruption of Mount St. Helens.

\section{Acknowledgements}

Thank you to the University of Puget Sound for a Summer Research Grant that supported this project, to Charlie Crisafulli and the US Forest Service at Mount St. Helens National Monument for providing us with a boat to allow our fieldwork to happen, to Lincoln Pickering and Colin Glaze for assisting with my field and lab work, to Amy Repogle for instruction and help using the confocal microscope, and to the University of Puget Sound Geology Department because it rocks. 